\title{
Consultants' views of Leave of Absence and Community Care Orders in Scotland
}

\author{
Jacqueline M. Atkinson, W. Harper Gilmour, James A. T. Dyer, \\ Fiona Hutcheson and Lesley Patterson
}

\begin{abstract}
Following consultation in 1994, changes were proposed to mental health legistation. In Scotiand these included the limitiation of Leave of Absence (LOA) to 12 months and the introduction of Community Care Orders (CCOs). All consultants in general poychiatiy in scotland were surveyed regarding their vows on LOA and CCOs. The results of our survey showed that the majortly of consultants use LOA and extended LOA, glving lack of insight and threat of stopping medication as the main reasons. Consultants reject both $\mathrm{CCO}$ and the limitations on LOA. Those who have been consultants for more than 16 years are significantly more likely to agree with restriction of LOA than others.
\end{abstract}

On 8 November 1995 the Mental Health (Patients in the Community) Bill recelved Royal Assent and became law from 1 April 1996. The triggering event was Ben Silcock's entry into the lions' den at London Zoo on 31 December 1993, although a climate of concern had been aroused following a number of cases of attacks by psychiatric patients on members of the public. Earlier that month Christopher Clunis had attacked and killed Jonathan Zito. Virginia Bottomley (then Secretary of State for Health) immediately demanded an investigation into possible changes to the Mental Health Act but biased the enquiry by decreeing that community treatment orders were not on the agenda (Department of Health, 1993) despite their previous support from the Royal College of Psychiatrists (1987). Views on ways of supervising patients in the community differ (e.g. Bluglass 1993; Burns et al 1993; Bynoe, 1993; Groves, 1993; Thornicroft, 1993; Crepaz-Keay, 1994; Holloway, 1994; Thompson, 1995) and will not be detailed here. In the Department's review the views of psychiatrists were sought, but the process was hurried; consultation started on 4 January 1993 and the government published Legal Powers on the Care of Mentally II People in the Community (Department of Health, 1993), colloquially known as 'Mrs Bottomley's Ten Point Plan' on 12 August 1993. It should be noted here that supervision registers, proposed in this plan, were not introduced into Scotland.

Mental Health Law is different in Scotland than England, particularly regarding the use of Extended Leave of Absence (ELOA), which is Leave of Absence (LOA) over six months. Legislation for England and Wales currently places a six month limit on continuous LOA, while in Scotland the legislation allows for repeated renewal for periods of up to six months at a time. Leave of absence has to be notified to the Mental Welfare Commission for Scotland (MWC) and the Commission visits patients to monitor their care at six months then at six monthly intervals. At the end of 1994 . 129 people had been on LOA for more than 12 months. The change in the Bill to allow LOA for 12 months only thus represents an increase for England and Wales but in Scotland is a constriction of current use of LOA. The Community Care Orders (CCOs) proposed for Scotland are broadly similar to discharge under supervision for England and Wales, but with flexible as opposed to specified conditions, and the orders have to be approved by a Sheriff. Against this background of consultation regarding proposed changes, a survey was conducted to obtain the views of consultants working in Scotland regarding LOA. ELOA and CCOs.

\section{The study}

\section{Subjects}

All consultant psychiatrists working in adult general psychiatry in Scotland were included. Those working solely in child and adolescent psychiatry, learning disability, psychotherapy, psychiatry of old age and for the MWC were excluded. The total contacted was 275.

\section{Survey}

A questionnaire was desiged to elicit information on use of LOA. ELOA and the proposed changes to limit ELOA to 12 months and to introduce CCOs. The questionnaire was discussed with 
several consultants and changes made to improve clarity. The final questionnaire was sent out in March 1995 with a three week return date. At the end of this time a reminder letter was sent. The questionnaires were returned anonymously.

\section{Findings}

\section{Respondents}

Of the 275 consultants surveyed, 238 (86.5\%) replied. Forty-five of these were not applicable, by reason of the person having retired, being on long-term sick leave, not working in adult general psychiatry or not being in post long enough to comment. Thus a total of 193 questionnaires were analysed.

The range of years as a consultant was 1-30, with a median of 9 years. Ninety-two per cent worked in the NHS, the remainder being employed by universities or the MRC.

\section{Use of Mental Health Act powers}

The majority of psychiatrists detain patients (183. $95 \%)$ and of these, 165 (85\% of total) use LOA and 125 (65\% of total) use ELOA. The number of patients currently on LOA for any one psychiatrist ranged from 0-14 with a median of 1 , and for ELOA from 0-11 with a median of 1 .

Psychiatrists were given a list of possible reasons why they might use LOA and ELOA. Table 1 gives the combined responses for 'applies in all cases' and 'applies in most cases' for LOA and ELOA.

Not all psychiatrists who do not use LOA and ELOA gave a reason. For those who detain but do not use LOA the main reason was that it was not applicable to their category of patients $(13 / 18$, $72 \%)$ or that the need had not yet arisen $(5 / 18$, $28 \%$ ). The main reason for not using ELOA by psychiatrists who use LOA was that patients have an appropriate care plan $(16 / 40,40 \%)$. A few psychiatrists, however, were concerned about the legality of ELOA; 'LOA is an infringement of civil liberties' (4/40, 10\%); 'ELOA is legally insupportable' (3/40, 7.5\%), and There may be a legal challenge to using $\mathrm{LOA}^{\prime}(3 / 40,7.5 \%)$.

The reasons applying in all or most cases for recalling patients on ELOA are given in Table 2.

Asked whether they saw a need for local guidelines on the use of ELOA, 112 (58\%) agreed (95\% CI 51-65). Of those who do not detain, 90\% $(9 / 10)$ thought guidelines necessary compared with $56 \%(103 / 183)$ of those who do detain $\left(\chi^{2}=4.43, P=0.035\right)$. The difference in views of guidelines was also significant $\left(\chi^{2}=5.67, P=0.017\right)$ between those who use LOA $(54.5 \%)$ and those who do not, whether or not they detain $(22 / 28$. 79\%).
Table 1. Psychiatrists' reasons for putting patients on Leave of Absence and Extended Leave of Absence (combined responses for "applies in all cases" and "applles in most cases")

\begin{tabular}{|c|c|c|c|c|}
\hline & \multicolumn{2}{|l|}{ LOA } & \multicolumn{2}{|l|}{ ELOA } \\
\hline & $n=165$ & (\%) & $n=125$ & (\%) \\
\hline Lack of Insight & 139 & (84) & 108 & (86) \\
\hline Risk of starvation & 6 & (4) & 6 & (5) \\
\hline Risk of sulcide & 26 & (16) & 18 & (14) \\
\hline Threat to others & 30 & (18) & 32 & (26) \\
\hline Threat to self & 61 & (37) & 43 & (34) \\
\hline Threat of stopping medication & 144 & (87) & 111 & (88) \\
\hline
\end{tabular}

Table 2. Psychiatrists' reasons for recalling patients on Extended Leave of Absence (combined responses for "applies in all cases" and "applies in most cases")

\begin{tabular}{lcc}
\hline & $n=125$ & (7) \\
\hline In-patient assessment & 46 & $(37)$ \\
Renewal of detention & 12 & $(10)$ \\
Risk of starvation & 2 & $(2)$ \\
Risk of suicide & 13 & $(10)$ \\
Self-neglect & 37 & $(30)$ \\
Stopping medication & 85 & $(68)$ \\
Threat to self & 37 & $(30)$ \\
Threat to others & 23 & $(18)$ \\
\hline
\end{tabular}

\section{Proposed changes}

Psychiatrists were asked whether they agreed with a limit to continuous LOA of 12 months, whether they supported CCOs, which lacked a compulsory treatment order, and whether they saw a continued need for ELOA if CCOs were introduced. The results are presented in Table 3.

Consultant psychiatrists overwhelmingly reject the proposed changes, with $78 \%$ rejecting limitation of ELOA (95\% CI, 72-84) and 86\% rejecting CCOs (95\% CI, 81-91). There is, however, a highly significant difference between those who use ELOA (18\%) and those who use LOA but not ELOA $(40 \%)$ for limiting ELOA $\left(\chi^{2}=13.2\right.$, $P=0.0002)$. The majority of respondents commented on their answers, and the lack of power to ensure compliance with medication was the overwhelming reason for rejecting $\mathrm{CCOs.}$

As well as the use of MHA powers, length of time as a consultant had an effect on their response to the changes. When consultants were grouped by the number of years they had been a consultant ( $1-5$ years $(n=64), 6-15$ years $(n=85)$ and over 16 years $(n=44))$ there was a significant difference on agreeing with proposals to limit ELOA to 12 months $\left(\chi^{2}=16.82, P=0.002\right)$ with agreement increasing with length of years as a consultant (1-5 years 9\%, 6-15 years 22\%, over 16 years $40 \%$ ). Length of years as a consultant 
Table 3. Consultants who agree with the proposed changes

\begin{tabular}{|c|c|c|c|c|c|c|}
\hline \multirow[b]{2}{*}{ Consultionts } & \multicolumn{2}{|c|}{$\begin{array}{l}\text { Limit Leave of } \\
\text { Absence to } 12 \\
\text { months }\end{array}$} & \multicolumn{2}{|c|}{$\begin{array}{l}\text { Community Care } \\
\text { Orders }\end{array}$} & \multicolumn{2}{|c|}{$\begin{array}{l}\text { Continued need for Extended Leove } \\
\text { of Abeence even with Community } \\
\text { Care Orders }\end{array}$} \\
\hline & $\bar{n}$ & (\%) & $n$ & (\%) & $n$ & (\%) \\
\hline $\begin{array}{l}\text { Total }(n=193) \\
\text { Detain }(n=183) \\
\text { Do not detain }(n=10) \\
\text { Use LOA }(n=165) \\
\text { No LOA but do detain }(n=18) \\
\text { No LOA } \\
\text { Use ELOA }(n=125) \\
\text { Do not use ELOA }(n=40)\end{array}$ & $\begin{array}{r}43 \\
39 \\
4 \\
38 \\
1 \\
5 \\
22 \\
16\end{array}$ & $\begin{array}{r}(22) \\
(21) \\
(40) \\
(23) \\
(6) \\
(18) \\
(18) \\
(40)\end{array}$ & $\begin{array}{r}27 \\
24 \\
3 \\
23 \\
1 \\
4 \\
17 \\
6\end{array}$ & $\begin{array}{r}(14) \\
(13) \\
(30) \\
(14) \\
(6) \\
(14) \\
(14) \\
(15)\end{array}$ & $\begin{array}{r}133 \\
128 \\
5 \\
116 \\
12 \\
17 \\
97 \\
19\end{array}$ & $\begin{array}{l}(69) \\
(70) \\
(50) \\
(70) \\
(67) \\
(61) \\
(78) \\
(47)\end{array}$ \\
\hline
\end{tabular}

had no impact on support for CCOs (1-5 years $17 \%, 6-15$ years $9 \%$, over 16 years $18 \%$ ). The need to keep ELOA if CCOs are introduced approached significance $\left(\chi^{2}=8.26, P=0.08\right)$ in the direction of the percentage of those agreeing decreasing as the number of years as a consultant increased (1-5 years 77\%, 6-15 years $72 \%$, over 16 years $52 \%$ ).

\section{Comments}

\section{Reasons for using Leave of Absence}

Most consultants in adult psychiatry detain patients and use both LOA and ELOA. 'Lack of insight' and 'stopping medication' are the most common reasons for using such powers. They are not in themselves, however, sufficient reason to put someone on LOA and presumably some other reason must apply. Even if we treat the four categories (threat of starvation, suicide, harm to others or self separately and assume consultants only ticked one (in fact they could have ticked more than one) then this still only totals 123. less than the response for lack of insight and stopping medication. Can we assume the consultants are simply missing out the major reason (e.g. threat to others) which would follow on from stopping medication? Any other interpretation would be worrying since it would not, of course, be legitimate for psychiatrists to be insisting on treatment compliance in people who are capable of consenting or refusing to consent to treatment and who did not otherwise merit compulsory detention. The Mental Welfare Commission, however, in monitoring use of LOA. finds it almost always to be justified in terms of the Mental Health Act. It is also worth noting, in the light of media attention on the danger to the public, that threat to self is greater than threat to others.

For those who do not use ELOA it does not seem to be legal considerations or concerns about ctvil liberties which prevent use, but the fact that it is not currently needed. This is supported by comments made on the questionnaire; half of those who did not use it said they would under some circumstances. Where this was given it was predominately to ensure compliance with medication. Only six (3\% of total population) said they would definitely not use ELOA.

Medication remains the issue for recalling patients, and again threat to self takes precedence over threat to others. One aspect of 'reasons for recalling patients on ELOA' which gives concern is 'renewal of detention', since it should not be necessary. If consultants who ticked 'applies in a few cases' are included then $23 \%$ gave this as a potential reason for recall. The generally accepted view in Scotland is that recall to hospital is not necessary for renewal of detention, although the actual wording of the renewal section of the Act is somewhat inconsistent with the leave of absence section and thus raises the possibility of a legal challenge.

\section{Views on new measures}

Taken as a whole, Scottish psychiatrists continue to support LOA and ELOA and reject the proposed CCOs. As might be expected, those who use ELOA are most likely to see a continued need for it and are also least likely to see the need for guidelines. The psychiatrists who do not detain overwhelmingly supported guidelines and are the most likely to support CCOs, although this is still a minority and the very small numbers mean this should be treated with caution. With hindsight it would have been interesting to include all consultants and thus include others who do not detain, notably the psychotherapists. The question is raised why those who do not detain do not. Even if it simply reflects their patient population, have such psychiatrists deliberately chosen to work with groups of people where detention is unlikely, and if so, why? 
Impact of years spent as a consultant

The impact of experience is interesting as results indicate that those who have been consultants longest show a decreasing support for ELOA. There are at least two possible explanations. The first might be that with experience comes greater skill in dealing with difficult to manage patients and the older psychiatrists are better able to manage such patients without resorting to legal measures. A second, and more cynical explanation, (provided by psychiatrists themselves when discussing the results) would be that with greater length of service comes loss of enthusiasm for the care of such patients with consequent loss of commitment. The survey sheds no light on which explanation is to be preferred.

\section{The future of the Mental Health Act}

Since the survey was completed (and results forwarded to the Scottish Office) the law has been changed to limit use of ELOA and to introduce $\mathrm{CCOs}$ without the power to ensure compliance with medication.

The current Mental Health Act comes from a legislative history which focuses on compulsory treatment in hospital. If patients are to be cared for in the community, including being supervised in the community, then it may be time for a new formulation of the law which focuses on individual needs and services meeting these needs rather than focusing on institutions. This has already been suggested by Blom-Cooper (1995) and the Mental Welfare Commission for Scotland (1995). For the present there is a need to monitor the use of the new powers in the Mental Health (Patients in the Community) Act in view of psychiatrists' overwhelming rejection of them. There is concern in Scotland that not only may the interests of those currently on leave of absence beyond 12 months suffer, but so too might the public acceptance of the whole policy of community care, should there be further untoward incidents affecting members of the public.

\section{References}

BLOM-COOPER, L. (1995) The Falling Shadow. London: Duckworth.

BuGGLSS, R. (1993) New powers of supervised discharge of mentally 111 people. Brttish Medical Journal, s07, 1160.

BuRns, T., GODDARD, K. \& BalEs, R. (1993) Mental health professionals favour community supervision orders. Brittsh Medical Journal, $307,803$.

BYNOE, I. (1993) Supervised discharge: what does it mean? Openmind, 65. 6.

Crepaz-Keay, D. (1994) "I wish to register a complaint ..." Openmind, 71, 5.

DEPARTMENT OF HEALTH (1993) Legal Powers on the Care of Mentally III People in the Community: Report of the Internal Review. H93/908 12th August. London: HMSO.

GROVES, T. (1993) Government wants wider legal powers for community care. Brttish Medical Joumal, 307, 803.

HoL OWAY, F. (1994) Supervision reglsters: recent government policy and legislation. Psychiatric Bullettr. 18. 593-596.

MENTAl Welfare COMmission FOR SCOTLAND (1995) Annual Report. Edinburgh: MWC.

ROYAL COLEGE OF PSYChIATRISTS (1987) Community Treatment Orders. London: RCPsych.

ThOMPson, A. (1995) Learn your lesson. Community Care. 1082. 8.

THORNICROFT, G. (1993) Community supervision orders. British Medical Journal, 307, 1213.

- Jacqueline Atkinson, Senior Lecturer, W. Harper Gilmore, Senior Lecturer, Department of Public Health, University of Glasgow; James Dyer, Director, Mental Welfare Commission for Scotland, 25 Drumsheugh Gardens, Edinburgh; Flona Hutcheson, Research Assistant and Lesley Patterson, Research Assistant, Department of Public Health, University of Glasgow, 2 Lilybank Gardens, Glasgow G12 8RZ

*Correspondence 